\title{
Climate change ... what can we do?
}

There are so many other problems besetting the NHS just now that talking about sustainability and environmental policies is diversionary. Right? Wrong.

As speaker after speaker emphasised at the conference organised by the Climate and Health Council ${ }^{1}$ which took place on the 29 January 2008 and held at the Royal College of Physicians, 'Climate change and its impact on health', what is good health advice for individual patients, eating less fat, cycling, controlling fertility, is also good for the health of the planet.

The editor of The Lancet, Richard Horton, said, 'Climate change is about social and environmental justice and doctors need to be advocates for their patients and their countries and create a social movement across the health sector'. Fiona Godlee, editor of the BMJ, quoted GMC guidelines. One of the two duties of a doctor laid down by them is 'to protect and promote the health of .... the public'. 'Gone are the days when doctors care only for the health of individual patients. Climate change should be on the agenda of every health meeting'.

The NHS as a whole has huge energy consumption and vast spending power and implementing sustainable policies makes not only good environmental but also good economic sense. The Sustainable Development Commission has been set up to take this initiative forward in six areas, transport, procurement, facilities management, employment and skills, community engagement, and new buildings. Are you a good corporate citizen? Take the test at www.corporatecitizen.nhs.uk. ${ }^{2}$

Both the Royal College of Physicians and the Royal College of Paediatrics and Child Health have undertaken to become carbon neutral with the $\mathrm{RCPCH}$ appointing a champion for carbon footprint reduction who is addressing paper use, improved use of technology, recycling, food and travel policy, and electricity and gas usage. Increasingly, large international conferences at exotic, carbon-expensive locations are being spurned in favour of video-conferencing.

What else can we, as individual doctors, do? Mike Gill, retired regional director of public health, wrote recently on behalf of the Climate and Health Council in the BMJ 'We should inform our professional colleagues and the wider community about the health consequences of climate change ... we should set an example by reducing our personal carbon footprints and ensuring that the organisations we work for do likewise. Thirdly, we should advocate ... Fourthly, health professionals should seek innovative approaches to using our many networks ... to recruit as many ... as possible'. ${ }^{3}$

As GPs, what is our role? Perhaps encourage our College to follow the lead of sister colleges in embracing a sustainable agenda? While environmental campaigning can never intrude into precious consultation time, we, as advocates for our patients, have close contact with our local communities and our views have influence. As Glasgow Professor of Public Health, Phil Hanlon, said at the conference, 'Economic growth associated with rising consumerism and individualism seems to be damaging our sense of wellbeing and the cohesion of our society'. He believes that sustainable policies will improve, not only environmental and physical, but also mental and spiritual, health. Definitely the business of general practice.

Dr Mark Thompson, a GP in Powys, offers a good example. His practice has an environmental policy, 'A blueprint for a green practice', which sets out 12 steps towards a carbon-light surgery. These address energy use, transport, recycling, encouraging patients attending for travel advice to consider offsetting, and minimising unnecessary journeys to the surgery. $\mathrm{He}$ is pleased that the RCGP Road Map for their vision for the future of primary care included a reference to carbon emissions; and he has submitted to the QOF Committee a proposal that QOF points should be awarded for carbon emissions reduction.
Practices like the car-free Dalkeith Road Practice in Edinburgh, which rely on bikes and occasional taxis to do their visits, would earn their points. Rural practices are more car-dependent but Borders Time, the Borders wide Continuing Professional Development programme, is about to promote a green practice award open to any practice with an innovative carbon reduction scheme.

Such ideas, and many others, will be shared at a conference in June on 'Carbon reduction and health, a guide to reducing the footprint of the health sector', organised by the $B M J$, the $\mathrm{RCPCH}$, and the Faculty of Public Health. Legislation against smoking eventually happened when doctors, and the public, forced politicians to act. The sooner we achieve robust legislation to curb carbon dioxide the better. We don't have a lot of time.

\section{Lesley Morrison}

\section{REFERENCES}

1. Climate and Health Council: London, 2007. http://www.climateandhealth.org (accessed 7 Mar 2008).

2. Sustainable Development Commission. London: NHS, 2005. http://www.corporatecitizen.nhs.uk (accessed 7 Mar 2008).

3. Gill M, Godlee F, Horton R, Stot R. Doctors and climate change. BMJ 2007; 335: 1104-1105.

DOI: 10.3399/bjgp08X280056 